\title{
Clinical characteristics and evaluation of LDL-cholesterol treatment of the Spanish Familial Hypercholesterolemia Longitudinal Cohort Study (SAFEHEART)
}

Nelva Mata', Rodrigo Alonso ${ }^{2}$, Lina Badimón ${ }^{3}$, Teresa Padró ${ }^{3}$, Francisco Fuentes $^{4}$, Ovidio Muñiz ${ }^{5}$, Francisco Perez-Jiménez ${ }^{4}$, José López-Miranda ${ }^{4}$, Jose L Díaz ${ }^{6}$, Jose I Vidal ${ }^{7}$, A Barba ${ }^{8}$, Mar Piedecausa ${ }^{9}$, Juan F Sanchez ${ }^{10}$, Luis Irigoyen ${ }^{11}$, Eliseo Guallar ${ }^{12,13}$, José M Ordovas ${ }^{13,14}$ and Pedro Mata ${ }^{2^{*}}$

\begin{abstract}
Aim: Familial hypercholesterolemia (FH) patients are at high risk for premature coronary heart disease (CHD). Despite the use of statins, most patients do not achieve an optimal LDL-cholesterol goal. The aims of this study are to describe baseline characteristics and to evaluate Lipid Lowering Therapy (LLT) in FH patients recruited in SAFEHEART.

Methods and Results: A cross-sectional analysis of cases recruited in the Spanish FH cohort at inclusion was performed. Demographic, lifestyle, medical and therapeutic data were collected by specific surveys. Blood samples for lipid profile and DNA were obtained. Genetic test for FH was performed through DNA-microarray. Data from 1852 subjects (47.5\% males) over 19 years old were analyzed: 1262 (68.1\%, mean age 45.6 years) had genetic diagnosis of $\mathrm{FH}$ and 590 (31.9\%, mean age 41.3 years) were non-FH. Cardiovascular disease was present in 14\% of $\mathrm{FH}$ and in $3.2 \%$ of non-FH subjects $(\mathrm{P}<0.001)$, and was significantly higher in patients carrying a null mutation compared with those carrying a defective mutation ( $14.87 \%$ vs. $10.6 \%$, respectively, $\mathrm{P}<0.05)$. Prevalence of current smokers was $28.4 \%$ in FH subjects. Most FH cases were receiving LLT (84\%). Although 51.5\% were receiving treatment expected to reduce LDL-c levels at least $50 \%$, only $13.6 \%$ were on maximum statin dose combined with ezetimibe. Mean LDL-c level in treated FH cases was $186.5 \mathrm{mg} / \mathrm{dl}$ (SD: 65.6) and only 3.4\% of patients reached and LDL-c under $100 \mathrm{mg} / \mathrm{dl}$. The best predictor for LDL-c goal attainment was the use of combined therapy with statin and ezetimibe.
\end{abstract}

Conclusion: Although most of this high risk population is receiving LLT, prevalence of cardiovascular disease and LDL-c levels are still high and far from the optimum LDL-c therapeutic goal. However, LDL-c levels could be reduced by using more intensive LLT such as combined therapy with maximum statin dose and ezetimibe.

Keywords: Familial hypercholesterolemia, Coronary artery disease, LDL-receptor mutations, LDL-c goal, combined therapy

\footnotetext{
* Correspondence: pmata@fjd.es

¿2ipid, Clinic, Internal Medicine Department. IIS-Fundación Jiménez Díaz,

Madrid

Full list of author information is available at the end of the article
} 


\section{Background}

Heterozygous familial hypercholesterolemia (FH) is the most common genetic disorder associated with the development of premature CHD with an autosomal dominant mode of inheritance, and a prevalence of one case in 400 to 500 in the general population [1]. The disorder is caused by mutations in the gene that encodes the low-density lipoprotein receptor (LDL-r), leading to an increase in plasma low-density lipoprotein cholesterol (LDL-c) levels. To date, more than 800 different functional mutations of the LDL-r gene have been described worldwide, and more than 200 have been documented in Spain [2]. Life expectancy is shortened by 20 to 30 years in FH patients[3], and sudden death and myocardial infarction are the principal causes of death $[4,5]$. The genetic defect is probably the most important factor in the clinical expression of $\mathrm{FH}$; however, other genetic, environmental and metabolic factors could play an important role in modulating the atherosclerotic burden in this population[6-8]. Since 1990's, coronary mortality and total mortality in FH patients have markedly decreased in part due to the use of statins [9-11]. However, despite the use of statins, most of these patients do not achieve an optimal therapeutic LDL-c level [12] and still have a high risk for the development of premature CHD.

The SpAnish Familial HypErcHolEsterolaemiA CohoRt STudy (SAFEHEART), was designed to gain insight into the prognostic factors and mechanisms that influence the development of CHD and mortality in a well-defined FH population. The aims of this study are to describe baseline characteristics and to evaluate Lipid Lowering Therapy (LLT) in FH patients recruited in SAFEHEART.

\section{Methods}

\section{Study Design and Subjects Recruitment}

SAFEHEART is an open, multicenter, long-term prospective cohort study in a well-defined FH population, conducted in nineteen outpatient lipid clinics in Spain. Recruitment of subjects from $\mathrm{FH}$ families began in 2004 and is still ongoing. Inclusion criteria are: 1) index cases (IC) with genetic diagnosis of $\mathrm{FH}, 2$ ) relatives over 15 years old with genetic diagnosis of $\mathrm{FH}, 3$ ) relatives over 15 years old without a genetic diagnosis of FH (control group). Relatives with high cholesterol due to other causes in the control group were not excluded.

To assure and improve the quality of data, physicians attended to 3 different meetings where the different questionnaires and procedures were carefully explained. This study was approved by the local ethics committees and all eligible subjects gave written informed consent.

\section{Follow-up}

A Coordinating Centre was created to organize and to implement the follow-up of cases. A standardized phone call is made every year to the subjects to know any relevant changes in lifestyles, medication, and cardiovascular events. An active epidemiological surveillance system has been developed for the detection of fatal and non fatal cardiovascular events that are classified according to WHO-MONICA criteria [13].

Premature CHD is defined if one of the following events occurs in males before 55 years old and in females before 65 years old, 1) Myocardial infarction, proved by at least two of the following: classic symptoms (> 15 minutes); specific electrocardiographic changes; elevated cardiac enzymes ( $>2 \times$ upper limit of normal). 2) Angina pectoris, diagnosed as classic symptoms in combination with at least one unequivocal result of one of the following: exercise test, nuclear scintigram, dobutamine stress ultrasound scan, $>70 \%$ stenosis on a coronary angiogram. 3) Percutaneous coronary intervention or other invasive procedures and coronary artery bypass grafting.

\section{Measures and blood samples}

Demographic and clinical characteristics of subjects include: age, educational status, medical history focused on cardiovascular disease (CVD), classic cardiovascular risk factors (hypertension, type 2 diabetes, smoking status), physical examination and current treatment for hypercholesterolemia and other risk factors. History of CVD is obtained from medical charts provided by the subjects at inclusion. A quality of life (SF-12) [14], food frequency [Vázquez C, Alonso R, Garriga $\mathrm{M}$, de Cos A, de la Cruz JJ, Fuentes-Jiménez F, Mata P. Validation of a food frequency questionnaire in Spanish patients with Familial Hypercholesterolaemia. Nutr Metab Cardiovasc Dis, in press] and physical activity [15] surveys are recorded on standardized form. Physical examination includes weight $(\mathrm{kg})$, height $(\mathrm{cm})$, body mass index $(\mathrm{Kg} /$ $\mathrm{m}^{2}$ ) and waist circumference $(\mathrm{cm})$. Blood pressure is measured twice in supine position with an Omron MX3 sphyngomanometer.

Venous blood samples are taken after 12 hours of fasting. Serum, plasma and DNA samples are aliquotted and preserved at $-80^{\circ} \mathrm{C}$ in a biobank located at the Cardiovascular Research Center in Barcelona. DNA is isolated from whole blood using standard methods and the genetic diagnosis of $\mathrm{FH}$ is made using a DNA-microarray $^{2}$ (Progenika SA, Bilbao, Spain). Serum total cholesterol, triglycerides and HDL-cholesterol levels are measured in a centralized laboratory using enzymatic methods. Serum LDL-c concentration is calculated using the Friedewald formula [16]. 
Mutations were classified as receptor-negative or receptor defective depending on their functional class as reported previously[7]. Those mutations with non reported functional class in the literature were classified as "unknown".

\section{Lipid lowering therapy classification (LLT)}

Maximum statin dose was defined as previously described [12]: simvastatin $80 \mathrm{mg} /$ day, pravastatin 40 $\mathrm{mg} /$ day, lovastatin $80 \mathrm{mg} /$ day, fluvastatin $80 \mathrm{mg} /$ day, atorvastatin $80 \mathrm{mg} /$ day, rosuvastatin $20-40 \mathrm{mg} /$ day. Maximum statin (MS) dose combined with ezetimibe 10 $\mathrm{mg} /$ day was considered as maximum combined therapy (MCT). The following treatment was considered giving at least a 50\% reduction in LDL-c baseline-levels: simvastatin 20 or 40 or $80 \mathrm{mg} /$ day in combination with ezetimibe $10 \mathrm{mg} /$ day, pravastatin $40 \mathrm{mg} /$ day in combination with ezetimibe $10 \mathrm{mg} /$ day, fluvastatin $80 \mathrm{mg} /$ day in combination with ezetimibe $10 \mathrm{mg} /$ day, atorvastatin 40 or $80 \mathrm{mg} /$ day, atorvastatin 10 or $20 \mathrm{mg} /$ day in combination with ezetimibe $10 \mathrm{mg} /$ day, rosuvastatin 20 or 40 $\mathrm{mg} /$ day and rosuvastatin $10 \mathrm{mg} /$ day in combination with ezetimibe $10 \mathrm{mg} /$ day.

\section{Statistical analysis}

An initial descriptive analysis was carried out using number of cases and percentages for qualitative variables and mean and standard deviation for quantitative variables with a normal distribution. For those quantitative variables with a non normal distribution, median and interquartilic-range were estimated. Comparisons of frequencies between qualitative variables were carried out using the Chi-squared test. Mean values of quantitative variables were compared with the Student's t-test for independent data while median values were compared with the non-parametric median test. The relationship between variables was considered statistically significant if the $\mathrm{p}$ value $<0.05$.

A binary logistic regression analysis (forward) was conducted to determine the variables associated with the attainment of an LDL-c $<100 \mathrm{mg} / \mathrm{dl}$, including those variables proved to be statistically significant in bivariate analyses and possible confounders (age, gender, tobacco, diabetes mellitus, high blood pressure, presence of CAD, type of mutation, type of LLT). The magnitude of the association was estimated using the adjusted odds ratio (OR) with a confidence interval (CI) of 95\%. All statistical analyses were performed using the Statistical Package for the Social Sciences (SPSS v 18.0, Chicago, IL, USA).

\section{Results}

Up to 2010, the study has enrolled 2078 participants (1402 FH cases and 676 unaffected relatives from 402 families (Figure 1). Baseline clinical characteristics and
575

Index cases from Spanish $\mathrm{FH}$ registry contacted

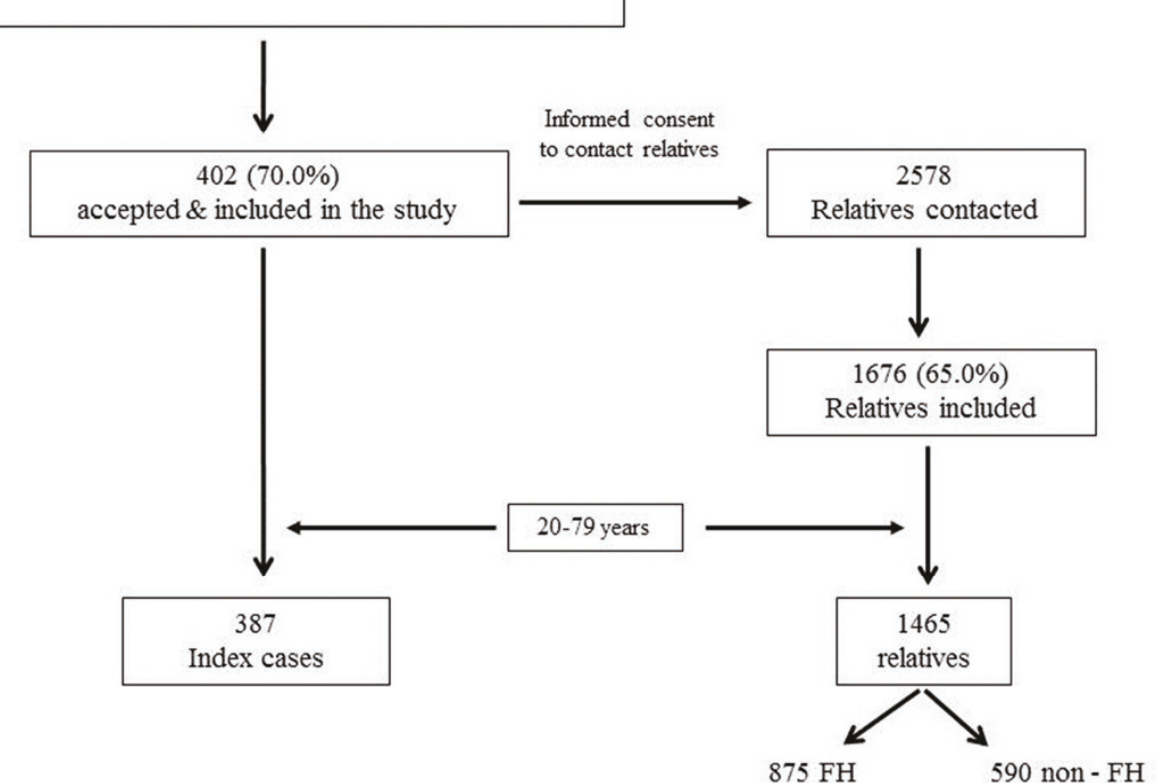

Figure 1 Recruitment of cases in the SAFEHEART study 
lipid profile of 1852 participants between 20 to 79 years are shown in Table 1 . No data for subjects aged $<20$ years are shown because no previous history of CVD was observed. There were no differences in gender between $\mathrm{FH}$ and control subjects. Mean age was 45.6 years (SD: 14.7) in FH subjects and 41.3 years old (SD: 14.7) in non FH subjects $(\mathrm{p}<0.001)$.

\section{Clinical and molecular diagnosis}

Most of the IC (88.3\%) and FH relatives (73.3\%) have been clinically diagnosed by the specialist. However, $25.4 \%$ of relatives with molecular diagnosis of $\mathrm{FH}$ (mean age 44.8 years, SD 15.9) did not know their clinical condition. Respect to genetic diagnosis, 120 different functional mutations in LDL-r and Apo B genes have been identified in this cohort and 25 mutations represent $65.0 \%$ of the cases recruited. Type of mutation was classified as receptor-negative or null mutations in $56.3 \%$ of FH subjects, while $35.2 \%$ had defective mutations.

\section{Classical risk factors and cardiovascular disease}

Prevalence of current smokers was $28.4 \%$ in FH subjects and $34.6 \%$ in the control group $(\mathrm{P}<0.001)$. There were no significant differences in the prevalence of type 2 diabetes and hypertension between both groups. HDL-c levels were lower in $\mathrm{FH}$ patients compared with controls $(\mathrm{P}<0.001)$ and there were no differences between $\mathrm{FH}$ subjects with null and defective LDL-r mutations (49.1 \pm 11.8 and $51.2 \pm 14.3 \mathrm{mg} / \mathrm{dl}$, respectively, $\mathrm{P}=0.208$ ).

History of CVD was present in $14.0 \%$ of $\mathrm{FH}$ patients, almost 5 times the prevalence found in non-FH subjects
( $\mathrm{p}<0.001)$. Coronary heart disease was the most frequent CVD (93.4\%) and it was premature in $80.0 \%$ of cases. First cardiovascular event occurred earlier in index cases (IC) compared with $\mathrm{FH}$ and non-FH relatives $(\mathrm{P}<0.001)$ (Table 1$)$. Prevalence of cardiovascular disease, especially CHD was higher in patients carrying null mutations than those carrying defective mutations in LDL-r gene $(14.8 \%$ vs. $10.6 \%$ respectively, $\mathrm{P}<0.05)$.

\section{Lipid lowering therapy}

At inclusion, 1056 (83.7\%) FH cases (97.0\% of IC and $78.0 \%$ of relatives) were receiving LLT compared to $18.8 \%$ of non-FH subjects ( $\mathrm{p}<0.001$ ). Nearly all cases on LLT were receiving statins $(95.4 \%)$, either in monotherapy $(58.3 \%)$ or in combined therapy $(37.0 \%)$, especially with ezetimibe $(31.3 \%)$. The most frequent prescribed statins were Atorvastatin (57.3\%), Simvastatin (28.9\%) and Rosuvastatin (2,9\%). Mean doses of statins were: Atorvastatin $44.8 \mathrm{mg}$ (SD: 25.8), Simvastatin 40.7 mg (SD: 23.3) and Rosuvastatin $28.8 \mathrm{mg}$ (SD: 12.7). Only $13.4 \%$ of $\mathrm{FH}$ subjects were receiving MS dose, and $13.6 \%$ were receiving $\mathrm{MCT}$.

\section{LDL-c levels and LDL-c goal achievement}

LDL-c level was not available in $91 \mathrm{FH}$ cases.

Mean LDL-c level was $220.7 \mathrm{mg} / \mathrm{dl}$ (SD: 72.5) in those $\mathrm{FH}$ cases that were not receiving LLT (16.3\%) compared to $186.5 \mathrm{mg} / \mathrm{dl}$ (SD: 65.6) of LDL-c level in FH cases on LLT $(83.7 \%)$. Of those FH patients receiving LLT, only $33(3.4 \%)$ had an LDL-c level $<100 \mathrm{mg} / \mathrm{dl}$, while 149 (15.5\%) had an alternative LDL level < $130 \mathrm{mg} / \mathrm{dl}$. On

Table 1 Baseline characteristics of subjects recruited in SAFEHEART (20 to 79 years old, $N=1852$ )

\begin{tabular}{|c|c|c|c|c|}
\hline & Index Cases N = 387 & FHR (+) N = 875 & FHR (-) N = 590 & P-value \\
\hline Gender (male)\% & 52.2 & 46.3 & 46.3 & 0.117 \\
\hline $\begin{array}{l}\text { Mean age (years) * } \\
\text { (Age range) }\end{array}$ & $\begin{array}{c}49.1 \pm 12.9 \\
(20.2-78.0)\end{array}$ & $\begin{array}{c}44.1 \pm 15.2 \\
(20.1-79.0)\end{array}$ & $\begin{array}{c}41.3 \pm 14.7 \\
(20.2-78.5)\end{array}$ & $<0.001$ \\
\hline Previous Clinical Diagnosis of FH (\%) & 100 & 74.6 & 13.9 & $<0.001$ \\
\hline History of CVD (\%) & 21.7 & 10.6 & 3.2 & $<0.001$ \\
\hline Age of first Cardiovascular event (Age range) & $\begin{array}{l}42.8 \pm 9.7 \\
(24.0-67.0)\end{array}$ & $\begin{array}{c}50.3 \pm 11.6 \\
(28.0-76.0)\end{array}$ & $\begin{array}{l}53.9 \pm 8.5 \\
(39.0-69.0)\end{array}$ & $<0.001$ \\
\hline Previous LLT (\%) & 96.9 & 77.8 & 18.8 & $<0.001$ \\
\hline Type 2 Diabetes (\%) & 2.1 & 4.0 & 3.6 & 0.220 \\
\hline High Blood Pressure (\%) & 14.7 & 14.6 & 12.7 & 0.531 \\
\hline Tobacco (current/past)(\%) & $20.2 / 33.3$ & $32.0 / 21.0$ & $34.6 / 17.1$ & $<0.001$ \\
\hline Xanthomas (\%) & 20.7 & 12.8 & 0.0 & $<0.001$ \\
\hline $\mathrm{BMI}\left(\mathrm{Kg} / \mathrm{m}^{2}\right) *$ & $26.7 \pm 4.3$ & $26.6 \pm 5.00$ & $26.2 \pm 5.2$ & 0.272 \\
\hline Total cholesterol $(\mathrm{mg} / \mathrm{dL})^{*}$ & $256.6 \pm 71.9$ & $264.6 \pm 69.6$ & $213.3 \pm 46.4$ & $<0.001$ \\
\hline Triglycerides $(\mathrm{mg} / \mathrm{dL})^{* *}$ & $89.0(52)$ & $85.0(56)$ & $85.0(54)$ & 0.239 \\
\hline $\mathrm{LDL}-\mathrm{C}(\mathrm{mg} / \mathrm{dL})^{*}$ & $188.0 \pm 69.9$ & $193.8 \pm 66.9$ & $131.3 \pm 41.4$ & $<0.001$ \\
\hline $\mathrm{HDL}-\mathrm{C}(\mathrm{mg} / \mathrm{dL})^{*}$ & $48.6 \pm 13.6$ & $50.3 \pm 13.9$ & $51.1 \pm 13.9$ & 0.001 \\
\hline
\end{tabular}

FH, Familial Hypercholesterolemia; FHR, Familial Hypercholesterolemia relatives; CVD, Cardiovascular Disease; LLT, Lipid lowering therapy; BMI, Body Mass Index; LDL-C, cholesterol transported on low-density lipoproteins; HDL-C, cholesterol transported on High Density Lipoproteins. ${ }^{*}$ values are expressed as Mean and standard deviation; ** values are expressed as Median and interquartilic range. 
the other hand, $270 \mathrm{FH}$ patients (29.0\%) receiving combined therapy (of whom $47.7 \%$ were on MCT) did not reach LDL-c goal. Cases with an LDL-c > $160 \mathrm{mg} / \mathrm{dl}$ and $>200 \mathrm{mg} / \mathrm{dl}$ in the MCT group were 54 (41.5\%) and $21(16.1 \%)$, respectively. LDL-c levels in patients using combined therapy with ezetimibe was slightly higher but not significant in those FH subjects with defective mutation compared with null mutation (171.2 \pm 67.6 vs. $161.2 \pm 57.2$, respectively, $\mathrm{P}=0.227$ )

Characteristics of $\mathrm{FH}$ patients according to attainment of LDL-c goal are shown in Table 2. Patients with an LDL-c on target were older, had a higher prevalence of CVD history, type 2 diabetes mellitus, hypertension, and were mostly treated with combined therapy than those subjects not on target $(\mathrm{p}<0.05)$. The percentage of cases receiving LLT expected to reduce LDL-c levels at least $50 \%$ was $51.5 \%$ and was higher $(63.6 \%)$ in patients on goal compared to those patients not on target (49.9\%), although this difference was not statistically significant. However, LDL-c levels were lower in those patients with more intensive LLT $(174.0 \pm 62.2 \mathrm{mg} / \mathrm{dl}$ vs. $196.5 \pm 63.8 \mathrm{mg} / \mathrm{dl}$ in patients receiving medication to reduce LDL-C $\geq 50 \%$ or below, respectively). There were no differences in LDL-c goal attainment between cases with null and defective mutations. The attainment of LDL-c goal was slightly higher but not statistically significant in those cases treated by specialists compared to general practitioners (59.3\% vs $55.2 \%, \mathrm{P}=0.677$ ).

Logistic regression analysis showed that combined therapy using statin and ezetimibe was significantly associated with the achievement of LDL-c goal (OR adjusted: 2.22; IC95\%:1.10-4.48), after adjustment for age, sex, CVD and cardiovascular risk factors.

\section{Discussion}

SAFEHEART is a long-term prospective cohort of a molecularly well-defined FH population in Spain. The present study shows that although most of FH cases are on LLT, cardiovascular risk is still high, in part due to the high LDL-c levels. An LDL-c level below $100 \mathrm{mg} / \mathrm{dl}$ was reached by $3.4 \%$ of patients receiving treatment, and of those patients not at target, $71 \%$ were not receiving combined therapy with ezetimibe.

Compared with other FH prospective studies [5,9-11], this cohort establishes genetic diagnosis of all study participants, eliminating misclassification bias when clinical criteria that may include polygenic hypercholesterolemia or familial combined hyperlipidemia are used. It has been demonstrated that more than $30 \%$ of $\mathrm{FH}$ cases might be classified incorrectly if only clinical diagnosis is used compared with the use of genetic test [17]. In this cohort, the DNA test identified $25,4 \%$ of relatives that did not know their clinical condition, with a mean age of 45 years, that is higher than the age recommended for starting LLT in agreement with clinical guidelines [18]. DNA testing offers a definitive and specific diagnosis and those systems based on a DNA microarray have been demonstrated to be cost-effective [19]. This study confirms that Spanish FH subjects are genetically very heterogeneous as previously described $[2,7]$.

History of CVD was present in $14.0 \%$ of FH patients, almost 5 times the prevalence found in non-FH subjects.

Table 2 Characteristics of FH patients on LLT classified according to attainment of LDL-c goal

\begin{tabular}{|c|c|c|c|}
\hline & LDL-Ch $<100 \mathrm{mg} / \mathrm{dL}(\mathrm{N}=33)$ & $\mathrm{LDL}-\mathrm{Ch} \geq 100 \mathrm{mg} / \mathrm{dL}(\mathrm{N}=932)^{\mathrm{A}}$ & P-value \\
\hline Male gender, N(\%) & $18(54.5)$ & $454(48.7)$ & 0.510 \\
\hline Cases $\geq 45$ years, $\mathrm{N}(\%)$ & $24(72.7)$ & $492(52.8)$ & 0.024 \\
\hline Age $(y)^{*}$ & 54.7 (SD:14.5) & 47.4 (SD:14.2) & 0.004 \\
\hline History of CVD, N (\%) & $10(30.3)$ & $153(16.4)$ & 0.036 \\
\hline Type 2 Diabetes, N (\%) & $4(12.1)$ & $33(3.5)$ & 0.012 \\
\hline High Blood Pressure, N (\%) & $10(30.3)$ & $157(16.8)$ & 0.045 \\
\hline Current smokers, N (\%) & $5(15.2)$ & $239(25.6)$ & 0.173 \\
\hline BMI $\left(\mathrm{Kg} / \mathrm{m}^{2}\right)^{*}$ & 26.6 (SD:4.0) & 26.7 (SD:4.6) & 0.882 \\
\hline Control by Specialist, N (\%) & $16(59.3)$ & $293(53.2)$ & 0.677 \\
\hline Null/Defective mutations, N (\%) & $16 / 14(48.5 / 42.4)$ & $541 / 311(58.0 / 33.4)$ & 0.525 \\
\hline Years on statin treatment* & 7.9 (SD:8.1) & $6.8(S D: 6.3)$ & 0.334 \\
\hline$\geq 50 \%$ LDL-c reduction, N (\%) & $21(63.6)$ & $471(49.9)$ & 0.254 \\
\hline Monotherapy with Statins, N (\%) & $11(33.0)$ & $565(60.6)$ & 0.002 \\
\hline Maximum Statin dose, N (\%) & $1(3.0)^{\mathrm{B}}$ & $134(14.4)^{B}$ & 0.229 \\
\hline Combined Therapy, $N(\%)^{C}$ & $18(54.5)$ & $270(29.0)$ & 0.002 \\
\hline Maximum Therapy, N (\%) & $6(18)^{B}$ & $124(13.3)^{B}$ & 0.238 \\
\hline
\end{tabular}

FH, Familial hypercholesterolemia; LLT, Lipid-lowering therapy; CVD, Cardiovascular disease; BMI (Body mass index) (A) LDL-ch levels were uknown in 91 cases; (B) percentage calculated with total cases in each group. (C) Combined therapy includes only any statin + ezetimibe 10 mg; (D), Maximum therapy includes any statin at maximum dose + ezetimibe $10 \mathrm{mg} ;{ }^{*}$ Mean and Standard Deviation (SD). 
This high cardiovascular risk is explained in part by the genetic background and by the presence of other cardiovascular risk factor such as tobacco consumption. This study shows that FH subjects with null mutation have higher prevalence of PCVD as previously described [7]. Prevalence of current smokers is still very high in these subjects $(28.4 \%)$ and similar to the Spanish general population (29.5\%) [20]; therefore, it is necessary to implement appropriate early-intervention strategies based on therapeutic and lifestyle changes, specially focus on quitting smoking.

Another important factor that can affect the development of CHD is related to LLT. The Simon Broom Registry showed that mortality in $\mathrm{FH}$ was reduced significantly after the introduction of statins [9]. Besides, a recent publication showed that $\mathrm{FH}$ patients without clinical CVD that started statin therapy after 1990 had a $76 \%$ reduction in the risk of cardiovascular events although the dose of statin used was lower than the recommended in this population; however, there are no data for LDL-c goal attainment [11].

International Guidelines consider $\mathrm{FH}$ patients at high cardiovascular risk and therefore the optimal LDL-c goal should be $<100 \mathrm{mg} / \mathrm{dl}[21,22]$ or to achieve at least a $50 \%$ reduction in LDL-c levels [18]. This study shows that although most of FH Spanish patients are treated with LLT, only 3.4\% have an LDL-c below $100 \mathrm{mg} / \mathrm{dl}$; however, half of this population were receiving treatment to reduce LDL-C $\geq 50 \%$. The best predictor for goal attainment was the use of combined therapy with ezetimibe. A large cross-sectional study carried out in The Netherlands showed that $21 \%$ of FH patients achieved LDL-c goal [12]. This difference could be explained in part because $25 \%$ of Dutch patients were on maximum therapy, whereas this occurred only in $13.6 \%$ of Spanish patients. On the other hand, $71 \%$ of the cases that were not on target were not receiving combined therapy. The use of combined therapy with ezetimibe in this cohort is low, probably because until now there is no evidence of the benefit on atherosclerotic burden measured as intima-media thickness in this population [23]. However, it has been shown that co-administration of ezetmibe with a statin is effective in reducing the estimated risk for cardiovascular mortality measured by the Framingham model in hypercholesterolemic patients [24]. The recent ezetimibe's reimbursement approval for $\mathrm{FH}$ patients and the introduction of rosuvastatin in Spain will probably contribute to increase the attainment of LDL-c goal, or at least a more intensive LDL-c reduction.

Although this is a cross-sectional analysis, the longterm follow-up of this cohort will allow to determine the role of changes in lifestyle and the further effect of a more intensive LLT and LDL-c goal attainment in the reduction of cardiovascular morbidity and mortality.
The results of this study show that there is still room for improvement in $\mathrm{FH}$ treatment in terms of using more combined therapy and higher doses of statins.

\section{Conclusions}

In conclusion, most of this high risk $\mathrm{FH}$ population still have high LDL-c levels and did not achieve the optimum LDL-c target as recommended by international guidelines. The combination of a statin and ezetimibe was associated with the best attainment of LDL-c goal. There is a medical need for new LLT options in combination with current therapy to reach lower LDL-c levels together with a better control of other risk factors to prevent $\mathrm{CAD}$ in this population.

\section{Funding}

This study was supported by Fundación Hipercolesterolemia Familiar and grants G03/181, Hiperlipemias Genéticas Network from the Instituto de Salud Carlos III; and grant 08-2008 from Centro Nacional de Investigaciones Cardiovasculares (CNIC).

\section{Appendix}

\section{The SAFEHEART study group}

Fundación Jiménez Díaz, Madrid: PM, RA. Health Promotion and Epidemiology, Spanish Ministry of Health and Fundación Hipercolesterolemia Familiar, Madrid: NM. Centro de Investigación Cardiovascular CSICICCC, Hospital Sant Pau and IIB-Sant Pau, Barcelona: LB, TP. IMIBIC/Hospital Reina Sofía, Córdoba: FF, FPJ, JLM. Hospital Virgen del Rocío, Sevilla: OM, J. VillarOrtiz. Hospital Abente y Lago, A Coruña: JLD. Hospital de Lugo, Lugo: JIV, R. Argueso. Hospital San Pedro de Alcántara, Cáceres: JFS. Hospital San Pedro, Logroño: A. Brea, D. Mosquera. Hospital de Vitoria, Vitoria: LI. Hospital Comarcal Vega Baja, Orihuela: JM Cepeda. Hospital General de Albacete, Albacete: MAB. Hospital de Elche, Alicante: MP, AM Hidalgo. Hospital Central de Asturias, Oviedo: P Gómez-Enterría, C Martínez-Faedo. Hospital de Mérida, Badajoz: P Saenz. Hospital Clínico, Barcelona. D. Zambón. Hospital Ramón y Cajal, Madrid: C Vázquez, F. Arrieta. Hospital de Donostia, Donostia: F. Almagro. Hospital Ciudad Real, Ciudad Real: J Galiana. Hospital de Igualada: J. Panisello. Hospital Nuestra Señora de la Candelaria, Tenerife: F Pereyra, M Muros.

\section{List of Abbreviations}

FH: Familial hypercholesterolemia; IC: Index case; CHD: Coronary heart disease; LLT: Lipid lowering therapy; LDL-r: Low-density lipoprotein receptor; CVD: cardiovascular disease

\section{Acknowledgements}

We like to thank the Spanish Familial Hypercholesterolemia Foundation for assistance in the recruitment of participants, and to the $\mathrm{FH}$ families for their valuable contribution and participation. 


\begin{abstract}
Author details
'Department of Epidemiology, Madrid Health Authority and Fundación Hipercolesterolemia Familiar, Madrid, Spain. ${ }^{2}$ Lipid, Clinic, Internal Medicine Department. IIS-Fundación Jiménez Díaz, Madrid. ${ }^{3}$ Centro de Investigación Cardiovascular CSIC-ICCC, Hospital Sant Pau and IIB-Sant Pau, and CIBEROBN, ISC III, Barcelona, Spain. ${ }^{4}$ Lipid Unit, IMIBIC/Hospital Reina Sofía and CIBEROBN, ISC III, Cordoba. ${ }^{5}$ Internal Medicine Department. Hospital Virgen del Rocío, Sevilla, Spain. ${ }^{6}$ Internal Medicine Department. Hospital Abente y Lago, A Coruña, Spain. 'Endocrinology Department, Hospital de Lugo, Spain. ${ }^{8}$ Internal Medicine Department. Hospital General de Albacete, Spain. Internal Medicine Department. Hospital de Elche, Spain. ${ }^{10}$ Internal Medicine Department. Hospital de Cáceres, Spain. ${ }^{11}$ Endocrinology Department. Hospital de Vitoria, Spain. ${ }^{12}$ Departments of Epidemiology and Medicine. Johns Hopkins Bloomberg School of Public Health, Baltimore, MD, USA.

${ }^{13}$ Centro Nacional de Investigaciones Cardiovasculares (CNIC), Madrid, Spain. ${ }^{14}$ Nutrition and Genomics Laboratory, Jean Mayer USDA Human Nutrition Research Center on Aging, Tufts University, Boston, MA, USA.
\end{abstract}

\section{Authors' contributions}

$N M, R A, L B, F P J, J L M, E G, J O, P M$, provided support in the design of the study. NM, RA, PM, LB, FPJ, coordinated the execution of the project. NM and RA wrote the manuscript.

RA, FF, OM, JLD, JIV, MAB, MP, JFS, LI, PM, collection and data interpretation. $N M, R A, E G$, performed statistical analysis and data interpretation. LB, TP are responsible of the biobank, sample managing and DNA obtention. FPJ, JLM, FF are responsible for biochemical analysis.

All authors' read and corrected draft version and approved the final manuscript

\section{Competing interests}

The authors declare that they have no competing interests.

Received: 12 May 2011 Accepted: 10 June 2011 Published: 10 June 2011

\section{References}

1. Goldstein JL, Hobbs HH, Brown MS: Familial Hypercholesterolemia. In The metabolic and molecular basis of inherited disease. Volume II. Edited by: Scriver CR, Beaudet AL, Sly WS, Valle D. McGraw-Hill, New York; 2001:2863-2913.

2. Alonso R, Defesche J, Tejedor D, Castillo S, Stef M, Mata N, GomezEnterria P, Martinez-Faedo C, Forga L, Mata P: Genetic diagnosis of familial hypercholesterolemia using a DNA-array based platform. Clin Biochem 2009, 42:899-903.

3. WHO Human Genetic Program: Familial Hypercholesterolemia. WHO/HGN/ FH/CONS/98.7 Paris; 1997, Report of a WHO consultation.

4. Slack J: Risks of ischaemic heart-disease in familial hyperlipoproteinaemic states. Lancet 1969, 2:1380-2.

5. Scientific Steering Committee on behalf of the Simon Broome Register Group: The risk of fatal coronary heart disease in familial hypercholesterolaemia. BMJ 1991, 303:893-6.

6. Pimstone SN, Sun XM, du Souich C, Frohlich JJ, Hayden MR, Soutar AK: Phenotypic variation in heterozygous familial Hypercholesterolemia: a comparison of Chinese patients with the same or similar mutations in the LDL receptor gene in China or Canada. Arterioscler ThrombVasc Biol 1998, 18:309-15.

7. Alonso R, Mata N, Castillo S, Fuentes F, Saenz P, Muñiz O, Galiana J, Figueras R, Diaz JL, Gomez-Enterría P, Mauri M, Piedecausa M, Irigoyen L, Aguado R, Mata P: Cardiovascular disease in familial hypercholesterolaemia: Influence of low-density lipoprotein receptor mutation type and classic risk factors. Atherosclerosis 2008, 200:315-21.

8. Jansen AC, van Wissen S, Defesche J, Kastelein JJ: Phenotypic variability in familial hypercholesterolaemia: an update. Curr Opin Lipidol 2002, 13:165-71.

9. Scientific Steering Committee on behalf of the Simon Broome Register Group: Mortality in treated heterozygous familial hypercholesterolaemia: implications for clinical management. Atherosclerosis 1999, 142:105-12.

10. Neil A, Cooper J, Betteridge J, Capps N, McDowell I, Durrington P, Seed M, Humphries SE: Reductions in all-cause, cancer, and coronary mortality in statin-treated patients with heterozygous familial hypercholesterolaemia: a prospective registry study. Eur Heart J 2008, 29:2625-33.
11. Versmissen J, Oosterveer DM, Yazdanpanah M, Defesche JC, Basart DC, Liem AH, Heeringa J, Witteman JC, Lansberg PJ, Kastelein JJ, Sijbrands EJ: Efficacy of statins in familial hypercholesterolaemia: a long term cohort study. BMJ 2008, 337:a2423.

12. Piljman $A H$, Huijgen $R$, Verhagen $S N$, Imholz BP, Liem AH, Kastelein JJ, Abbink EJ, Stalenhoef AF, Visseren FL: Evaluation of cholesterol lowering treatment of patients with Familial hypercholesterolemia: A large crosssectional study in the Netherlands. Atherosclerosis 2010, 209:189-94.

13. Böthig S, WHO MONICA Project: WHO MONICA Project: objectives and design. Int J Epidemiol 1989, 18(suppl 1):29-37.

14. Vilagut $G$, Valderas JM, Ferrer M, Garin O, López-García E, Alonso J: Interpretation of SF-36 and SF-12 questionnaires in Spain: physical and mental components. Med Clin (Barc) 2008, 130:726-35.

15. Rütten A, Ziemainz H, Schena F, Stahl T, Stiggelbout M, Auweele YV Welshman J, Ziemainz $\mathrm{H}$ : Using different physical activity measurements in eight European countries. Results of the European Physical Activity Surveillance System (EUPASS) time series survey. Public Health Nutr 2003, 6:371-6.

16. Friedewald WT, Levy RI, Fredrickson DS: Estimation of the concentration of low-density lipoprotein cholesterol in plasma, without use of the preparative ultracentrifuge. Clin Chem 1972, 18:499-502.

17. Leren TP: Cascade genetic screening for familial hypercholesterolemia. Clin Genet 2004, 66:483-7.

18. Wierzbicki AS, Humphries SE, Minhas R: Familial hypercholesterolaemia: summary of NICE guidance. BMJ 2008, 337:a1095.

19. Oliva J, López-Bastidas J, Gutierrez S, Mata P, Alonso R: Cost-efectiveness analysis of a genetic screening program in the close relatives of Spanish patients with familial hypercholesterolemia. Rev Esp Cardiol 2009, 62:57-65.

20. Spanish National Health Survey: Spanish Ministry of Health, Social Policy and Equality. 2006 [http://www.msc.es/estadEstudios/estadisticas/ encuestaNacional/encuestalndice2006.htm].

21. Civeira F: Guidelines for the diagnosis and management of heterozygous familial hypercholesterolemia. Atherosclerosis 2004, 173:55-68.

22. Graham I, Atar D, Borch-Johnsen K, Boysen G, Burell G, Cifkova R, Dallongeville J, De Backer G, Ebrahim S, Gjelsvik B, Herrmann-Lingen C, Hoes A, Humphries S, Knapton M, Perk J, Priori SG, Pyorala K, Reiner Z, Ruilope L, Sans-Menendez S, Scholte op Reimer W, Weissberg P, Wood D, Yarnell J, Zamorano JL, Walma E, Fitzgerald T, Cooney MT, Dudina A, European Society of Cardiology (ESC) Committee for Practice Guidelines (CPG): European guidelines on cardiovascular disease prevention in clinical practice: executive summary. Fourth Joint Task Force of the European Society of Cardiology and Other Societies on Cardiovascular Disease Prevention in Clinical Practice. Eur Heart J 2007, 28:2375-414.

23. Kastelein JJ, Akdim F, Stroes ES, Zwinderman AH, Bots ML, Stalenhoef AF, Visseren FL, Sijbrands EJ, Trip MD, Stein EA, Gaudet D, Duivenvoorden R, Veltri EP, Marais AD, de Groot E, ENHANCE Investigators: Simvastatin with or without ezetimibe in familial hypercholesterolemia. N Engl J Med 2008, 358:1431-43.

24. Sampalis JS, Bissonnette S, Habib R, Boukas S, Ezetrol Add-On Investigators: Reduction in estimated risk for coronary artery disease after use of ezetimibe with a statin. Ann Pharmacother 2007, 41:1345-51.

doi:10.1186/1476-511X-10-94

Cite this article as: Mata et al: Clinical characteristics and evaluation of LDL-cholesterol treatment of the Spanish Familial Hypercholesterolemia Longitudinal Cohort Study (SAFEHEART). Lipids in Health and Disease 2011 10:94. 